Байкальский государственный университет, 2. Иркутск, Российская Федеращия

Г. В. Малышенко

Байкальский государственный университет,

2. Иркутск, Российская Федерация

\title{
К ВОПРОСУ О СУЩНОСТИ И МАСШТАБАХ ИСПОЛЬЗОВАНИЯ КРАУДСОРСИНГА
}

\begin{abstract}
АНнОТАЦИЯ. Краудсорсинг является альтернативой использования внутренних ресурсов компании для решения возникающих задач. Авторами проведено теоретическое исследование понятия, рассмотрены существующие точки зрения на его природу, выделены смыслообразующие критерии: организатор, участники, процесс. Предложено авторское определение краудсорсинга как формы взаимодействия заинтересованной в решении задач организации и предлагающих свои решения мотивированных участников, осуществляемого в интернет-пространстве. Обобщены результаты исследований распространенности данного явления в мире, сделан вывод о преимущественном распространении данного явления в отраслях, предлагающих товары повседневного спроса. Констатирован постепенный переход от краудсорсинга проектов (создания контента) к краудсорсингу идей. Представлены результаты собственного описательного исследования распространения явления в России, подтверждающего, что основными сферами использования краудсорсинг деятельности в России, как и на мировом рынке в целом, являются сферы ритейла, государственного и муниципального управления, а также банковская сфера. Определены направления дальнейшего исследования.

КЛЮчЕВЫЕ СЛОВА. Краудсорсинг; краудфандинг; инновации; интернет-активность. ИНФОРМАЦИЯ О СТАТЬЕ. Дата поступления 13 апреля 2017 г.; дата принятия к печати 28 апреля 2017 г.; дата онлайн-размещения 21 июня 2017 г.
\end{abstract}

O. N. Baeva Baikal State University, Irkutsk, Russian Federation G.V. Malyshenko Baikal State University, Irkutsk, Russian Federation

\section{ON ISSUE OF ESSENCE AND SCALES OF USING CROWDSOURCING}

\begin{abstract}
Crowdsourcing is an alternative to using company's internal resources for solving arising tasks. The authors carry out a theoretical investigation of the concept, consider the existing viewpoints of its nature, identify the sense-making criteria: organizer, participants, process. The article offers the authors' definition of crowdsourcing as a form of interaction of the organization interested in solving its tasks and the participants offering their solutions, with everything being performed in the Internet space. It generalizes the investigation results for distribution of this phenomenon in the world, draws a conclusion of prevailing distribution of this phenomenon in in the industries that offer their basic goods. It states a gradual transition from crowdsourcing of projects to crowdsourcing of ideas. The article presents the results of the own descriptive investigation of distribution of this phenomenon in Russia that confirms that the main spheres of using crowdsourcing activity in Russia, like in the world market on the whole, are the spheres of retail trade, governmental and municipal management as well as the banking sector. It also specifies the directions of further investigation.
\end{abstract}

(C) О. Н. Баева, Г. В. Мальшенко, 2017

\section{Baikal Research Journal}


KEYWORDS. Crowdsourcing; crowdfunding; innovations; Internet activity. ARTICLE INFO. Received April 13, 2017; accepted April 28, 2017; available online June 21, 2017.

В современных условиях компании все чаще задумываются о способах наиболее эффективного осуществления своей деятельности. Одной из наиболее популярных и эффективных альтернатив использования внутренних ресурсов организации для решения возникающих задач является применение краудсорсинга - одного из методов массового сотрудничества, при котором изменяется «само видение того, как компании и общество в целом используют знание и способности для инноваций и создания ценности. Это влияет практически на каждый сектор экономики и каждый аспект управления. Развивается новый вид бизнеса, открывающий двери всему миру, сотрудничающий с каждым (в особенности, с собственными клиентами), делящийся ресурсами, прежде скрытыми за семью замками, получающий огромную выгоду от массового сотрудничества и ведущий себя не как традиционная международная компания, а как глобальная компания нового типа. Компании подобного типа проводят наиболее значительные изменения в своих отраслях и переписывают многие правила конкуренции» [1, с. 28].

Понятие краудсорсинга впервые было использовано в 2006 г. Д. Хау и М. Робинсоном для описания новой модели ведения бизнеса посредством сети интернет, при которой для нахождения наиболее точного решения задачи используется открытый конкурс предложений [2]. В дальнейшем Д. Хау в своей книге определит краудсорсинг как предоставление компаниями и учреждениями возможности взятия на себя функций по решению возникающих проблем сотрудникам, а также иному кругу лиц в сети интернет в форме открытого конкурса [3]. Данная возможность может привести к объединению усилий для поиска наиболее успешного варианта решения поставленной задачи или же единоличному достижению той же цели, т. е. единоличному осуществлению работ по поиску наиболее эффективного способа разрешения поставленной проблемы. Важнейшими условиями приобретения услуг данного формата, по мнению Д. Хау, являются: наличие большой сети потенциальных работников, а также форма открытого конкурса при выборе наиболее эффективного способа осуществления работ.

В настоящее время насчитывается большое количество трактовок краудсорсинга. Анализ имеющихся расхождений явился предметом двух исследований. Первое из них проведено в 2012 г. [4]. Выявлено, что в период с 2006 по 2011 г. было предложено порядка 40 определений понятия краудсорсинг, большая часть которых имела достаточно схожее значение. Рассматриваемые трактовки имели расхождения только при использовании понятия краудсорсинг применительно к различным типам деятельности. Авторы отобрали восемь основных отличительных характеристик понятия, сгруппировав их в три блока: связанные с участниками («толпой») (участник, его действия, мотивация); связанные с организаторами (организатор, его выгоды) и связанные с краудсорсинг-процессом (тип процесса (происходящий в режиме онлайн или основанный на живом участии), степень открытости конкурса, роль интернета в краудсорсинг-процессе). Приняв во внимание и обобщив все вышеперечисленные отличительные характеристики, авторы предложили более универсальное определение: «Краудсорсинг - это один из видов интернет активности, основанный на участии, при котором физическое лицо, учреждение, некоммерческая организация или коммерческая компания предлагает в форме открытого конкурса группе участников, которая может варьироваться по уровню знаний, размеру и составу, выполнить задание. Данное задание может различаться по сложности и структуре. Для его выполнения, участни-

\section{Baikal Research Journal}

электронный научный журнал Байкальского государственного университета 
кам следует применить собственный труд, денежные средства и/или имеющиеся знания (в том числе жизненный опыт). Выполнение поставленного задания всегда влечет за собой взаимную выгоду. Участник имеет возможность удовлетворить свои потребности экономического и социального плана, а также развить индивидуальные навыки. В свою очередь краудсорсер будет иметь возможность использовать в своих интересах все то, что сделают участники (форма конечного продукта будет зависеть от вида осуществляемой деятельности)».

Еще одно исследование, посвященное анализу сущности краудсорсинга, выполнено в 2016 г. [5]. Рассмотрев 32 понятия, авторы выделили существенные характеристики: участники, цели, инициаторы, выгоды инициаторов, тип вызова, используемые средства, продолжительность. На основе этих характеристик дано общее, непротиворечивое определение, позволяющее установить принадлежность какой-либо деятельности к краудсорсингу: «это процесс аутсорсинга задачи или проблемы, которые необходимо решить группе людей, участвующих в этом процессе через Интернет для получения прибыли, который длится до тех пор, пока компании не получают решение». Данное определение представляется очень упрощенным, поскольку процесс краудсорсинга не может рассматриваться как простая передача функций по поиску решения. Он может быть реализован только при соответствующей продуманной и хорошо организованной схеме взаимодействия компании с людьми, помогающими в решении задач. По сути, речь идет о новой форме социального взаимодействия, выходящей рза рамки простого делегирования задач. На наш взгляд, следует рассматривать краудсорсинг как форму взаимодействия заинтересованной в решении задач организации и предлагающих свои решения мотивированных участников, осуществляемую в интернет-пространстве.

По мнению Д. Хау, краудсорсинг подразделяется на четыре основные модели, общей чертой которых является то, что все они основаны на участии большого количества людей. $\kappa$ основным моделям краудсорсинга относятся: краудфандинг, творчество «толпы», голосование «толпы», мудрость толпы (коллективный разум). (Под «толпой» понимается любая группа, состоящая из условно-анонимных или незнакомых друг с другом участников). Выбор модели для поведения напрямую зависит от конечной цели проведения краудсорсинг-проекта.

Краудфандинг - это коллективное сотрудничество людей, которые добровольно отдают свои средства (деньги и другие ресурсы), как правило, через интернет, чтобы поддержать проекты других людей или компаний [6]. Данная модель краудсорсинга наиболее успешно применяется в финансировании творческих проектов, стартапов и социальных некоммерческих проектов. Также в последнее время набирает все большую популярность краудфандинг в научной сфере. Одним из ярчайших примеров проведения краудфандинга в данной сфере является сбор денежных средств в ноябре 2012 г. на проект разработки плазменного двигателя для ракет и автоматических космических станций HyperV: удалось собрать порядка 72 тыс. дол., из первоначально планируемых 69 тыс. дол. Из российской практики использования краудфандинга с целью инвестирования научного проекта, можно привести пример сбора финансовых средств на российской краудфандинговой платформе Boomstarter для осуществления запуска космического спутника «Маяк». Проект был завершен в марте 2016 г., было собрано около 2 млн р. из первоначально запланированных 1,5 млн р.

Творчество «толпы» это модель осуществления краудсорсинг-проекта, под которой подразумевается объединение творческого потенциала людей, зачастую абсолютно независимых друг от друга, для создания чего-либо. Объектами создания участников краудсорсинг-проектов могут являться разнообразные лого-

\section{Baikal Research Journal}

электронный научный журнал Байкальского государственного университета 
типы, дизайны упаковок, фотографии и т. д. Одним из примеров использования творчества «толпы» можно считать открытый конкурс для всех желающих, запущенный оргкомитетом «Токио-2020», суть которого заключается в разработке логотипа для Олимпийских и Паралимпийских Игр, которые пройдут в 2020 г. в Токио.

Голосование «толпы» способ принятия решения путем учета общественного мнения. При этом обоснование собственного мнения и предложение альтернативных решений в обязательном порядке от участников голосования, как правило, не требуются. Примером данной модели краудсорсинг-активности может послужить открытое голосование на выбор символов для новых купюр номиналом 200 и 2000 р. Голосование проводилось в несколько этапов. Его участниками стало около 3,3 млн чел.

Последней в данной классификации и самой сложной в плане реализации моделью проведения краудсорсинг-проектов является применение мудрости «толпы» или коллективного разума для поиска оптимального решения поставленных задач. По мнению Д. Хау, основным принципом данной модели является то, что «у группы знаний больше, чем у отдельного человека». Наибольший эффект от реализации данной модели краудсорсинга будет достигнут в случае появления синергетического эффекта между мнениями «гениев из толпы» и экспертными мнениями сотрудников организации. Это позволит выйти за рамки узкой экспертной квалификации и взглянуть на имеющуюся задачу совершенно под другим углом. При таком подходе вероятность решения задачи новым, нетипичным способом резко возрастает, что может стать ключом к успеху организации, которая осуществляет свою деятельность в условиях современного, постоянно модернизирующегося рынка.

Одним из примеров применения мудрости «толпы» является деятельность итальянской автомобильной компании Fiat. На сайте Fiat Mio с момента начала его функционирования (начало 2009 г.) было насчитано около 2 млн уникальных посетителей, представивших более десяти тысяч идей, связанных с осуществлением деятельности компании, которые в перспективе могут превратить автомобили и без того относительно крупного и успешного производителя в еще более качественный и востребованный продукт.

Создание компанией Yota сервиса, на котором каждый желающий может внести свои предложения по внедрению каких-либо нововведений в деятельность, осуществляемую компанией, а также оценить уже имеющиеся предложения, позволило внести целый ряд разнообразных изменений, в числе которых: возможность перехода на Yota с сохранением номера и без визита в офис, выпуск SIM-карт для планшета, возможность тест-драйв услуг, предоставляемых оператором и т. д.

На протяжении последних четырех-пяти лет интерес к каждой из моделей краудсорсинга остается стабильно высоким. К такому выводу можно прийти, проанализировав статистику запросов, представленную на сервисах Google Trends и Yandex Wordstat. Все это объясняется положительным эффектом от использования данных способов решения проблем.

Однако, говоря о развитии краудсорсинга в России, следует отметить, что в настоящее время накопленный опыт в реализации данного типа проектов слишком мал, информация о выгодах компаний отсутствует. Также одной из проблем является то, что использование краудсорсинга зачастую дает запоздалый экономический эффект, так как результатом является всего лишь решение задачи, которая только в перспективе может принести положительные денежные потоки организации. Большинство существующих в настоящее время крауд-проектов ре-

\section{Baikal Research Journal}


ализуются с помощью упрощенной классической схемы, которая базируется на предложении участниками разнообразных идей, которые впоследствии подвергаются фильтрации и дальнейшей оценке, путем простейшего онлайн-голосования. Такой подход к реализации краудсорсинг-проектов в большей степени способствует проявлению наряду с несомненными достоинствами данного инструмента ряда недостатков (табл. 1).

Таблица 1

Преилущества и недостатки использования краудсорсинга

\begin{tabular}{|l|l|}
\hline \multicolumn{1}{|c|}{ Преимущества } & \multicolumn{1}{|c|}{ Недостатки } \\
\hline Наличие большого количества идей. & Сложность контроля и отбора предлагаемых \\
Новый взгляд на имеющиеся проблемы & идей. \\
Экономия бюджета. & Возможность утечки информации. \\
Выстраивание стратегии развития про- & Сложность мотивирования участников на \\
дукта исходя из набора и приоритетности & результат. \\
пожеланий потребителей. & Низкий КПд коллективной работы множества \\
Возможность сокращения времени на & людей. \\
поиск решения проблемы. & Свойство людей выбирать более простое и \\
Увеличение лояльности потребителей & понятное (әффект Матфея) \\
\hline
\end{tabular}

Имеющиеся недостатки в значительной степени снижают эффективность использования данного инструмента. И все же полезный эффект от применения краудсорсинга, несомненно, есть.

Косвенным подтверждением положительного эффекта краудсорсинга является рост масштабов его использования в мировой практике. По результатам исследований «State of Crowdsourcing 2016» ${ }^{1}$, проводимого краудсорсинг платформ Eyeka в деятельности, осуществляемой крупными мировыми компаниями, были замечены следующие особенности.

1. Компании, предоставляющие продукцию повседневного пользования, расширили свою краудсорсинг деятельность. Традиционно пионерами краудсорсинга принято считать такие бренды как Microsoft, Google, Samsung. Эти компании начали использовать новшества в применении творческого потенциала «толпы» начиная с середины 2000-х гг. Впоследствии к ним присоединилась и начала вести активную деятельность в этом направлении копания Apple. По данным, представленным в «State of Crowdsourcing 2016» наблюдается тенденция к бурному росту использования краудсорсинг-технологий FMCG-компаниями. В то время, как технологические бренды вернулись к уровню 2013 г., FMCG-бренды, такие как Coca-Cola, Danone и Nestle увеличили использование творческого краудсорсинга в сравнении с предыдущими годами (рис. 1).

Компании сектора FMCG, а также технологические компании в должной степени оценили влияние краудсорсинга на результаты осуществляемой деятельности в целом. Применение краудсорсинг-технологий в индустрии СМИ и развлечений началось многим позже, однако, темпы роста их использования показывают нарастающую положительную динамику. В других секторах экономики наблюдается тенденция к постепенному спаду популярности краудсорсинга. Так приведенные выше цифры показывают, что в сфере финансов, страхования производства, энергетики отрицательная динамика применения краудсорсинга наблюдается на протяжении ряда лет. Также в 2015 г., после небольшого роста, было отмечено значительное сокращение использования творческого потенциала «толпы» в сферах автомобилестроения и ритейла.

${ }^{1}$ The State of Crowdsourcing in 2015. URL: https://ru.eyeka.com/resources/reports ; The State of Crowdsourcing in 2016. URL: https://ru.eyeka.com/resources/reports.

\section{Baikal Research Journal}


70

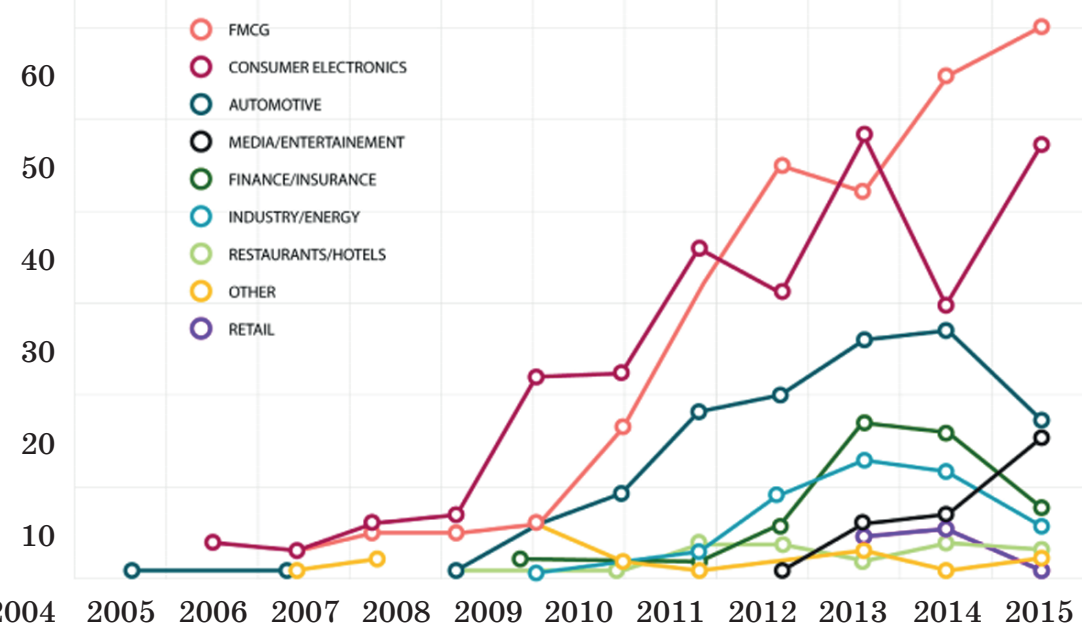

200420052006200720082009201020112012201320142015

Рис. 1. Динамика использования краудсорсинга в различных секторах рынка в период с 2004 по 2015 г.

2. Бренды, которые активно использовали краудсорсинг технологии в 20042014 гг., к 2015 г. увеличили использование данного инструмента в среднем еще на $30 \%$. При рассмотрении краудсорсинг-активности отдельных компаний следует отметить сохранение лидерства в 2015 г. за компанией Coca-Cola (рис. 2). Средний процент прироста краудсорсинг-активности среди 20 ведущих брендов, отмеченный в конце 2015 г. составил примерно $30 \%$. Наиболее впечатляющий прирост по данному показателю показала компания Johnson\&Johnson, которая увеличила в 2015 г. количество проводимых краудсорсинг-проектов почти в три раза (прирост составил 186 \%) по сравнению с результатом, зафиксированным за период 2004-2014 гг.

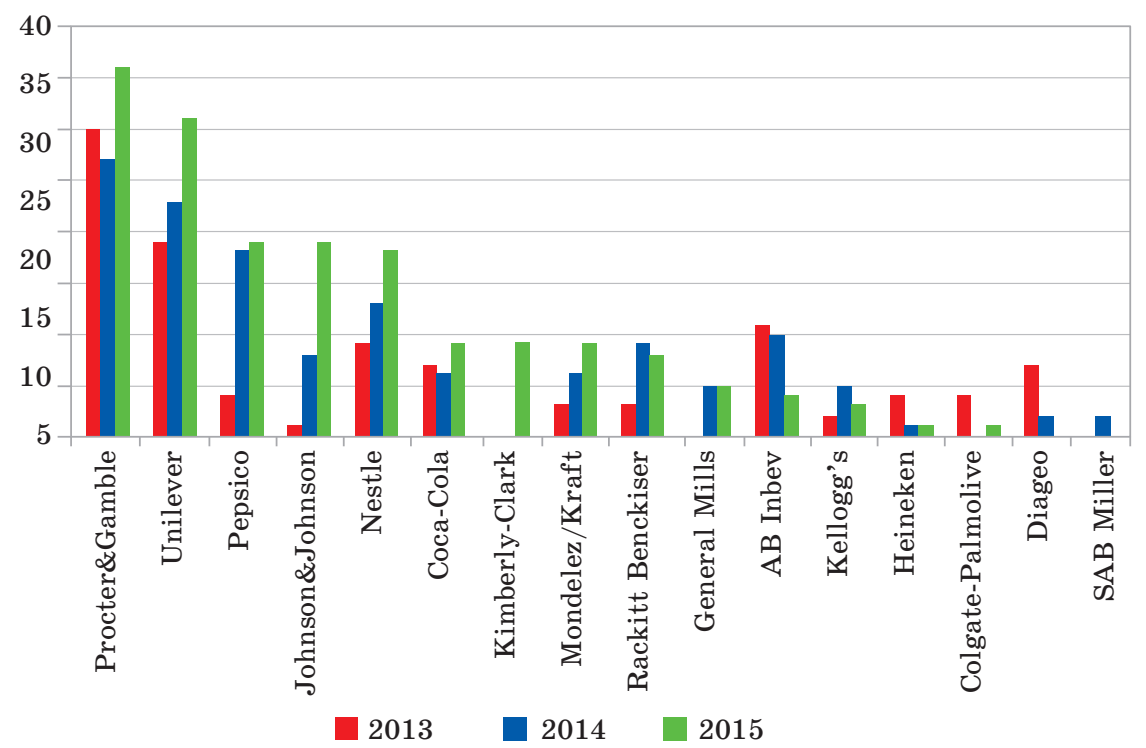

Рис. 2. Краудсорсинг-деятельность ведущих FMCG-компаний в 2013-2015 г2.

\section{Baikal Research Journal}


3. Замечен ежегодный рост использования краудсорсинга в сфере FMCG. В докладе 2015 г. было отмечено увеличение использования краудсорсинга среди десяти наиболее крупных FMCG компаний в период с 2013 по 2014 г. в среднем на $48 \%$. В 2016 г. к ранее отмеченным добавились еще шесть ярко проявивших себя FMCG компаний (такие как Johnson\&Johnson, Heineken, Colgate-Palmolive и др.). Использование краудсорсинга в шестнадцати наиболее крупных FMCG компаниях возрастает из года в год. В период 2013-2014 гг. средний прирост составил $30 \%$, и около $27 \%$ в период 2014-2015 гг.

4. Рассмотрение деятельности отдельных FMCG-компаний приводит к выводу о том, что помимо многочисленных примеров увеличения использования краудсорсинг технологий существуют также примеры сокращения краудсорсинг-активности. Рассматривая краудсорсинг-деятельность отдельных FMCG-компаний по годам (см. рис. 2), можно отметить устойчивые позиции компаний Procter \& Gamble и Unilever, показатели краудсорсинг-активности которых, за трехлетний период сохраняли лидирующие позиции. Большая часть компаний, участвовавших в исследовании, увеличила использование краудсорсинга в 2015 г. по сравнению с 2013 и 2014 г. Это может служить подтверждением того, что FMCG-компании находят эффективным использование краудсорсинг-проектов в своей деятельности. Однако существуют примеры и сокращения краудсорсинг-активности. Так AB InBev и Heineken на протяжении исследуемого периода ежегодно сокращали количество проводимых краудсорсинг-мероприятий. Помимо этого, 2015 г. был отмечен снижением использования краудсорсинга в деятельности таких компаний как Kellogg's и Colgate-Palmolive; компании Diageo и SAB Miller отказались от проведения краудсорсинг-проектов. Данный факт, возможно, свидетельствует о том, что не всем компаниям удается полноценно внедрить творчество «толпы» в свою деятельность.

5. Постепенный переход от краудсорсинга контента к краудсорсингу идей. По данным «The State Of Crowdsourcing 2015» в период 2004-2014 гг. большую популярность приобрели краудсорсинг-проекты, конечной целью которых было создание контента. Однако в последнее время наблюдается смена тенденций, а именно: постепенный переход от краудсорсинга контента к краудсорсингу идей. Так, например, по данным исследований топ-16 FMCG-компаний в 2015 г. доля использования проектов краудсорсинга идей увеличилась почти в два раза (с 29 \% в 2014 г. до $48 \%$ - в 2015 г. при соответствующем снижении доли краудсорсинга проектов - с 71 до 52 \%). Предлагаемые идеи затрагивают самые разнообразные аспекты деятельности компаний: разработка дизайна упаковки, изменение способов коммуницирования с имеющимися и потенциальными потребителями, создание принципиально новых продуктов, работ, услуг и т. п.

Исследование, проведенное авторами, свидетельствует о том, что основными сферами использования краудсорсинг деятельности в России, также как и на мировом рынке в целом, являются сферы ритейла, государственного и муниципального управления, а также банковская сфера.

Среди российских компаний ПАО «Сбербанк» был одним из первых, кто начал активно использовать краудсорсинг в своей деятельности. В 2010 г. компанией, возглавляемой Г. О. Грефом, был реализован внутренний краудсорсинг проект по использованию идей собственных сотрудников, результатом которого стала экономия 1 млрд р. Проект «Сбербанк 21», проведенный в 2011 г., помог сэкономить в уже в семь раз больше. Проект был выведен за пределы компании: его реализация привлекла 120 тыс. участников из 64 стран мира, при этом самые креативные предложения 2011 г. послужили основой для долгосрочных планов развития и легли в основу стратегии ПАО «Сбербанк» на 2014-2019 гг. В 2012 г. банк про-

\section{Baikal Research Journal}

электронный научный журнал Байкальского государственного университета 
должил проект «Сбербанк 21», выделив несколько направлений (табл. 2), в рамках которых участникам предлагалось оставить свои предложения по улучшению качества услуг, предоставляемых банком.

Направления проекта “Сбербанк 21"

\begin{tabular}{|c|c|c|c|c|}
\hline $\begin{array}{c}\text { Название про- } \\
\text { екта }\end{array}$ & $\begin{array}{l}\text { Период } \\
\text { проведения } \\
\text { проекта }\end{array}$ & $\begin{array}{l}\text { Количество } \\
\text { участников }\end{array}$ & $\begin{array}{l}\text { Количество } \\
\text { предло- } \\
\text { жений по } \\
\text { решению } \\
\text { проблемы }\end{array}$ & Результаты \\
\hline Очередей. Нет! & $\begin{array}{l}\text { Август } \\
2012-\text { ок- } \\
\text { тябрь } 2012\end{array}$ & 5947 & Более 1500 & $\begin{array}{l}\text { Новые решения по предупреждению } \\
\text { и устранению причин появления } \\
\text { очередей в ПАО «Сбербанк» }\end{array}$ \\
\hline $\begin{array}{l}\text { Корпоративная } \\
\text { социальная от- } \\
\text { ветственность: } \\
\text { бизнес для об- } \\
\text { щего будущего }\end{array}$ & $\begin{array}{c}\text { Август } \\
2012-\text { ок- } \\
\text { тябрь } 2012\end{array}$ & 5368 & Более 1800 & $\begin{array}{l}\text { Формирование социальной сети для } \\
\text { реализации последующих обсужде- } \\
\text { ний, создание платформы первичных } \\
\text { предложений по развитию корпора- } \\
\text { тивной социальной ответственности } \\
\text { (КСО) и отдельных инициатив; выяв- } \\
\text { ление приоритетов групп «лиенты» } \\
\text { и «сотрудники» в отношении направ- } \\
\text { лений и инициатив КСО, предложе- } \\
\text { ния по усовершенствованию отчетов } \\
\text { КСО ПАО «Сбербанк» }\end{array}$ \\
\hline $\begin{array}{l}\text { Некредитные } \\
\text { продукты для } \\
\text { малого, средне- } \\
\text { го и крупного } \\
\text { бизнеса }\end{array}$ & $\begin{array}{c}\text { Сентябрь } \\
2012- \\
\text { ноябрь } 2012\end{array}$ & 4896 & Около 1700 & $\begin{array}{l}\text { Новые решения по улучшению } \\
\text { продуктов для привлечения средств } \\
\text { корпоративных клиентов и развитию } \\
\text { каналов дистанционного банковского } \\
\text { обслуживания в ПАО «Сбербанк» }\end{array}$ \\
\hline $\begin{array}{l}\text { Розничный } \\
\text { офис: комфорт } \\
\text { и качествен- } \\
\text { ный сервис }\end{array}$ & $\begin{array}{l}\text { Декабрь } \\
2012- \\
\text { март } 2013\end{array}$ & 2995 & Более 5200 & $\begin{array}{l}\text { Определение проблем розничных } \\
\text { офисов, требующих особого внима- } \\
\text { ния (планировка, навигация внутри } \\
\text { офисов, организация зоны самооб- } \\
\text { служивания) и предложения по их } \\
\text { устранению }\end{array}$ \\
\hline
\end{tabular}

Составлено по: Краудсорсинг в Сбербанке. URL: http://smb.sberbank21.ru/sbercrowd; Сбербанк собирает идеи: практика банковского краудсорсинга. URL: https://www.pcweek.ru/idea/article/ detail.php?ID=144760.

В настоящее время ПАО «Сбербанк» продолжает вести активную краудсорсинг деятельность. Одним из последних мероприятий в данном направлении является конкурс на разработку мобильного приложения «Сбербанк Бизнес Онлайн». Помимо этого, ведется непрерывное обсуждение, целью которого является поиск идей по оптимизации деятельности, разработки новых сервисов и услуг банка.

Кроме ПАО «Сбербанк» крупными краудсорсинг-проектами отличилась компания Аэрофлот. Реализуемый ею в 2015 г. проект «Полет мысли» привлек к участию 6989 чел. В результате было собрано около 13670 идей по различным направлениям деятельности компании. Так, например, одним из участников проекта была предложена идея о возможности подписки на уведомление об акциях, спецпредложениях на конкретные направления или даты, что было бы полезно и выгодно, например, для людей, планирующих поездку в отпуск заранее. Лучшей же стала идея, которая заключалась в обеспечении клиентов минитележками для ручной клади с наличием сиденья для ребенка в возрасте до 5 лет. Помимо этого, в 2016 г. этой же авиакомпанией были реализованы краудсорсинг-проекты по выбору новой версии дизайна собственного сайта, а также по осуществлению исследований, направленных на определение кулинарных предпочтений пассажиров бизнес-класса.

\section{Baikal Research Journal}

электронный научный журнал Байкальского государственного университета 
Популярность применения краудсорсинга растет и за пределами сферы бизнеса. Так, одним из основных способов применения краудсорсинга в сфере государственного и муниципального управления является обсуждение законопроектов и иных управленческих решений, прорабатываемых органами власти. Площадками для обсуждения являются как онлайн, так и оффлайн каналы связи с людьми, желающими принять участие в обсуждениях. Так, например, при обсуждении законопроекта о внесении изменений в Гражданский кодекс РФ были использованы официальные и неофициальные каналы взаимодействия через сеть Интернет, с целью привлечения экспертного сообщество обсуждение выдвигалось на различных конференциях и семинарах. С целью совершенствования законотворческой деятельности и обеспечения учета общественного мнения при подготовке проектов федеральных конституционных законов и федеральных законов Указом Президента РФ № 167 от 9 февраля 2011 г. была установлена полная процедура вынесения проектов федеральных конституционных законов на общественное обсуждение.

По данным 46-го Международного экономического форума, проведенного в январе 2017 г. в Давосе, отмечено, что ключевым драйвером предстоящих изменений в области промышленности станет соединение классической промышленности с цифровыми технологиями. Краудсорсинг является одним из инструментов реализации данного направления. Технология краудсорсинга рассматривается в качестве инструмента инновационного развития [7].

Несмотря на относительно недавнее появление краудсорсинга, данный инструмент с каждым годом набирает все большую популярность в различных сферах жизнедеятельности. По большей части такое развитие событий связано с усилением роли интернета и социальных сетей, технологий мобильной связи, а также с необходимостью использования более качественного и дешевого подхода к решению возникающих проблем.

Однако вероятность того, что реализация любой из моделей краудсорсинга без опоры на четкий алгоритм действий приведет организацию к успеху, крайне низка. Одним из вариантов проведения краудсорсинг-кампании может послужить алгоритм, представленный на рис. 3.

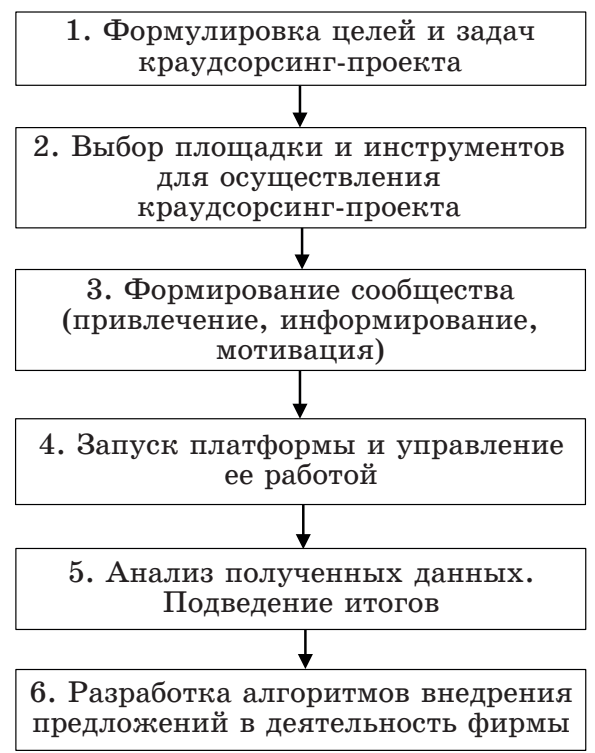

Рис. 3. Алгоритм проведения краудсорсинг-кампании

(Составлено по: [8;9])

\section{Baikal Research Journal}


1. Формулировка целей и задач краудсорсинг-проекта. Распределение ответственности. Программу по внедрению краудсорсинга следует начать с постановки цели и задач краудсорсинг-проекта. Цель - это своего рода базис деятельности организации. Четко сформулировав цель и вытекающие из нее задачи, можно ожидать от участников краудсорсинг-проекта понимания, к какому конкретно результату стремится организация, из этого следует, что нахождение наиболее оптимального решения имеющейся проблемы станет более вероятным. Помимо этого, наличие четко сформулированной цели позволит установить стандарты деятельности участников, а также бюджет, сроки и критерии оценивания результатов, получаемых в процессе осуществления краудсорсинг-проекта. Также на данном этапе следует провести отбор лиц ответственных за каждый из видов предстоящей деятельности.

2. Выбор площадки и инструментов для осуществления краудсорсинг проекта. Данный этап следует выполнять, полностью опираясь на предыдущий. Так как выбор площадки и инструментов в большей степени зависит от величины бюджета, выделяемого на проект, и конечной цели, к осуществлению которой стремится организация.

3. Формирование сообщества. Суть данного этапа сводится к привлечению внимания потенциальных участников путем их информирования через разнообразные коммуникационные каналы. Далее организаторами должны быть приняты меры для формирования максимально эффективного сообщества, состоящего из мотивированных на предстоящую работу участников, понимающих, что от них требуется.

4. Запуск платформы и управление ее работой. Данный этап включает в себя контроль над соблюдением сроков запуска платформы, а также над стабильностью ее функционирования, осуществляемого в рамках бюджета.

5. Анализ полученных данных. Подведение итогов. На данном этапе происходит оценка полученных результатов, отбор наиболее значимых и полезных идей, осуществление анализа возможности доработки отобранных идей, рассмотрение возможности внедрения предлагаемых нововведений в текущую деятельность и поощрение авторов лучших идей.

6. Разработка алгоритмов внедрения предложений в деятельность фирмы.

Заданный алгоритм дает наглядное представление о последовательности работ, обязательных для приведения в действие краудсорсинг-проекта. Это дает возможность более эффективно распределить имеющиеся ресурсы.

Одним из наиболее актуальных направлений исследований является мотивация участия населения в краудсорсинговых проектах [10-12]. Возникает закономерный вопрос о возможностях и масштабах использования краудсорсинга на уровне региона для решения экономических и социальных проблем, мотивах и стимулах участия потребителей (граждан) в краудсорсинговых проектах (для бизнеса и региональной власти). По мнению авторов, наиболее важным (и интересным с точки зрения дальнейшего научного исследования) является исследование мотивации граждан для участия в краудсорсинговых проектах по решению социальных проблем, разработка комплекса мероприятий, направленных на привлечение и поддержание интереса к взаимодействию с местной властью.

Список использованной литературы

1. Тапскотт Д. Викиномика. Как массовое сотрудничество изменяет все / Д. Тапскотт, Э. Д. Уильям. - M. : Best Business Books, 2009. - 392 c.

2. Howe J. The Rise of Crowdsourcing / J. Howe // Wired Magazine. - 2006. - Vol. 14, no. 6. - P. 1-4.

3. Хау Д. Краудсорсинг: Коллективный разум как инструмент развития бизнеса / Д. Хау. М. : Альпина Паблишер, 2012. - 288 с.

\section{Baikal Research Journal}


4. Estellés-Arolas E. Towards an integrated crowdsourcing definition / E. Estellés-Arolas, F. González-Ladrón-de-Guevara // Journal of Information Science. - 2012. — Vol. 20, № 10. - P. 189-201.

5. Świeszczak M. Crowdsourcing - what it is, works and why it involves so many people? [Electronic resource] / M. Świeszczak, K. Świeszczak // World Scientific News. - 2016. № 48. - P. 32-40. - Mode of access: http://psjd.icm.edu.pl/psjd/element/bwmeta1.element. psjd-0697cdfd-dbe7-4ea1-8ed8-9be1394d0141.

6. Буценко Е. В. Практическое применение краудфандинга как инновационного механизма финансирования (на примере развития сельских территорий региона) [Электронный ресурс] / Е. В. Буценко // Экономические исследования. - 2014. - № 3. - Режим доступа: http://www.erce.ru/internet-magazine/magazine/39/618/.

7. Немировская Е. П. Технология краудсорсинга как фактор инновационного развития: теоретический анализ / Е. П. Немировская // Baikal Research Journal. - 2016. T. 7, № 5. - DOI: 10.17150/2411-6262.2016.7(5).10.

8. Митева Ц. Краудсорсинг в бизнесе: коллективный разум спешит на помощь [Электронный ресурс] / Ц. Митева // Контур. - 2013. - 20 нояб. - Режим доступа: http:// kontur.ru/articles/415.

9. Полторак К. А. Применение крауд-технологий в маркетинговой деятельности предприятий / К. А. Полторак, О. В. Зозульов // Економічний вісник Національного технічного університету Украіни «Киівський політехнічний інститут». — 2014. — № 11 . C. $422-429$.

10. Быхтин О. В. Мотивация к участию в краудсорсинговых проектах / О. В. Быхтин // Научный результат. Сер.: Социология и управление. - 2014. - T. 1, № 1 (1). - С. 46-50.

11. Долженко Р. А. Способы мотивации участников краудсорсинговых проектов [Электронный ресурс] / Р. А. Долженко // Мотивация и оплата труда. — 2014. — № 1. - Peжим доступа: http://grebennikon.ru/article-ob25.html.

12. Acar O. A. Crowdsourcing for Innovation: unpacking motivational, knowledge and relational mechanisms of innovative behavior in crowdsourcing platforms [Electronic resource] / Oguz Ali Acar. - Rotterdam Erasmus University, 2014. - 10 p. - (Series ERIM Ph.D. Series Research in Management). - Mode of access: http://hdl.handle.net/1765/76076.

\section{References}

1. Tapscott Don, Williams Anthony D. Wikinomics: How Mass Collaboration Changes Everything. New York, Penguin, 2006. 320 p. (Russ. ed.: Tapskott D., Williams A. D. Vikinomika. Kak massovoe sotrudnichestvo izmenyaet vse. Moscow, Best Business Books, 2009. 392 p.).

2. Howe J. The Rise of Crowdsourcing. Wired Magazine, 2006, vol. 14, no. 6, pp. 1-4.

3. Howe J. Crowdsourcing: Why the Power of the Crowd is Driving the Future of Business. New York, Three Rivers Press, 2008. 280 p. (Russ. ed.: Howe J. Kraudsorsing. Kollektivnyi razum kak instrument razvitiya biznesa. Moscow, Alpina Publisher, 2012. 288 p.).

4. Estellés-Arolas E., González-Ladrón-de-Guevara F. Towards an integrated crowdsourcing definition. Journal of Information Science, 2012, vol. 20, no. 10, pp. 189-201.

5. Świeszczak M., Świeszczak K. Crowdsourcing - what it is, works and why it involves so many people? World Scientific News, 2016, no. 48, pp. 32-40. Available at: http://psjd. icm.edu.pl/psjd/element/bwmeta1.element.psjd-0697cdfd-dbe7-4ea1-8ed8-9be1394d0141.

6. Butsenko E. V. Practical use of crowdsourcing as an innovative financial mechanism (in terms of development of region's rural territories). Ekonomicheskie issledovaniya = Economic Investigations, 2014, no. 3. Available at: http://www.erce.ru/internet-magazine/magazine/39/618/. (In Russian).

7. Nemirovskaya E. P. Crowdsourcing technology as a factor of innovative development: a theoretical analysis. Baikal Research Journal, 2016, vol. 7, no. 5. DOI: 10.17150/24116262.2016.7(5).10. (In Russian).

8. Miteva Ts. Crowdsourcing in business: collective mind races to rescue. Kontur, 2013, November 20. Available at: http://kontur.ru/articles/415. (In Russian).

9. Poltorak K. A., Zozul'ov O. V. Use of crowd-technologies in marketing activities of enterprises. Ekonomichnii visnik Natsional'nogo tekhnichnogo universitetu Ukraini "Kiivs'kii politekhnichnii institut» = Economic Bulletin of National Technical University of Ukraine "Kyiv Polytechnical Institute», 2014, no. 11, pp. 422-429. (In Russian).

\section{Baikal Research Journal}


10. Bykhtin O. V. Motivation for participation in crowdsourcing projects. Nauchnyi rezul'tat. Seriya: Sotsiologiya i upravlenie = Research Result. Series: Sociology and Management, 2014, vol. 1, no. 1 (1), pp. 46-50. (In Russian).

11. Dolzhenko R. A.Ways of motivating participants of crowdsourcing projects. . Motivatsiya $i$ oplata truda = Motivation and Payment for Labor, 2014, no. 1. Available at: http:// grebennikon.ru/article-ob25.html. (In Russian).

12. Acar O. A. Crowdsourcing for Innovation: unpacking motivational, knowledge and relational mechanisms of innovative behavior in crowdsourcing platforms. Rotterdam Erasmus University, 2014. 10 p. Available at: http://hdl.handle.net/1765/76076.

\section{Информация об авторах}

Баева Ольга Николаевна - кандидат экономических наук, заведующий кафедрой менеджмента, маркетинга и сервиса, Байкальский государственный университет, 664003, г. Иркутск, ул. Ленина, 11, e-mail: baeva-on@mail.ru.

Мальшенко Галина Витальевна - студент, кафедра менеджмента, маркетинга и сервиса, Байкальский государственный университет, 664003, г. Иркутск, ул. Ленина, 11, e-mail: malyshenko.g@yandex.ru.

\section{Authors}

Olga N. Baeva- PhD in Economics, Head of Chair of Management, Marketing and Services, Baikal State University, 11 Lenin St., 664003, Irkutsk, Russian Federation; e-mail: baeva-on@mail.ru.

Galina V. Malyshenko - Student, Chair of Management, Marketing and Services, Baikal State University, 11 Lenin St., 664003, Irkutsk, Russian Federation; e-mail: malyshenko.g@ yandex.ru.

\section{Библиографическое описание статьи}

Баева О. Н. К вопросу о сущности и масштабах использования краудсорсинга / O. Н. Баева, Г. В. Малышенко // Baikal Research Journal. - 2017. - T. 8, № 2. — DOI: 10.17150/2411-6262.2017.8(2).27.

\section{Reference to article}

Baeva O. N., Malyshenko G. V. On issue of essence and scales of using crowdsourcing. Baikal Research Journal, 2017, vol. 8, no. 2. DOI: 10.17150/2411-6262.2017.8(2).27. (In Russian).

\section{Baikal Research Journal}

